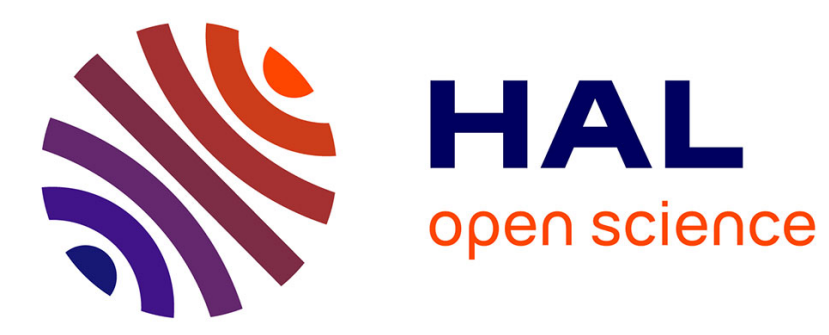

\title{
Reducing Intergroup Bias: The Moderating Role of Ingroup Identification
}

\author{
Richard J. Crisp, Sarah R. Beck
}

\section{To cite this version:}

Richard J. Crisp, Sarah R. Beck. Reducing Intergroup Bias: The Moderating Role of Ingroup Identification. Group Processes and Intergroup Relations, 2005, 8 (2), pp.173-185. 10.1177/1368430205051066 . hal-00571601

\section{HAL Id: hal-00571601 \\ https://hal.science/hal-00571601}

Submitted on 1 Mar 2011

HAL is a multi-disciplinary open access archive for the deposit and dissemination of scientific research documents, whether they are published or not. The documents may come from teaching and research institutions in France or abroad, or from public or private research centers.
L'archive ouverte pluridisciplinaire HAL, est destinée au dépôt et à la diffusion de documents scientifiques de niveau recherche, publiés ou non, émanant des établissements d'enseignement et de recherche français ou étrangers, des laboratoires publics ou privés. 


\title{
Reducing Intergroup Bias: The Moderating Role of Ingroup Identification
}

\author{
Richard J. Crisp and Sarah R. Beck \\ University of Birmingham
}

\begin{abstract}
Recent work developing interventions designed to reduce intergroup bias has sometimes yielded disparate findings. We tested whether the varying effectiveness of such interventions may have a motivational basis. In two experiments we examined whether differential ingroup identification moderated the effectiveness of a differentiation-reducing intervention strategy. In Experiment 1, thinking of characteristics shared between the ingroup and outgroup reduced ingroup favoritism to a greater extent for lower identifiers than for higher identifiers. In Experiment 2 we replicated this finding with different target groups and evaluative measures while controlling for information load. We discuss the implications of this work for developing social psychological models of bias-reduction.
\end{abstract}

KEYWORDS ingroup identification, intergroup bias, reducing prejudice, social categorization

The EXtent to which social categoriesingroups and outgroups-possess overlapping characteristics is a key determinant of how such groups are evaluated (Brewer, 1991; Tajfel \& Turner, 1979; Turner, Hogg, Oakes, Reicher, \& Wetherell, 1987). It is not surprising then that concepts of intergroup overlap and distinctiveness are central in defining not only our understanding of intergroup relations but also social psychologists' attempts at reducing intergroup bias. Models of contact (Brewer \& Miller, 1984; Hewstone \& Brown, 1986; Miller, Brewer, \& Edwards, 1985; Pettigrew, 1998), the formation of a common ingroup identity (Gaertner \& Dovidio, 2000; Gaertner, Mann, Dovidio, Murrell, \& Pomare, 1990; Gaertner, Mann, Murrell, \& Dovidio, 1989), and crossed categorization (Crisp \& Hewstone, 1999; Crisp,
Hewstone, \& Rubin, 2001; Deschamps \& Doise, 1978) include the notion that, albeit via different methods, emphasizing common ground between groups and group members can be a good thing. Recently, however, some findings have raised the possibility that reducing intergroup differentiation may not always be the key to improved intergroup relations, and that in some cases doing so could even make matters worse. In this article we examine this possibility and the moderating

\section{Author's note}

Address correspondence to R. J. Crisp, School of Psychology, University of Birmingham, Edgbaston, Birmingham B15 2TT, UK [email: r.crisp@bham.ac.uk] 
conditions that may influence the effectiveness of differentiation-based interventions for reducing intergroup bias.

\section{Social categorization and category differentiation}

Ever since Sherif's (1966) seminal summer camp studies, the link between category differentiation and ingroup favoritism has been an enduring feature of work on intergroup relations. Merely distinguishing between people on the basis of their group affiliations appears to be sufficient to produce ingroup favoritism. Tajfel's research with the Minimal Group Paradigm (Tajfel, Billig, Bundy, \& Flament, 1971) illustrated how even with no prior contact, under conditions of anonymity, and with meaningless social categories, the knowledge that 'they' are different to 'us' can translate into evaluative differentiation (see Brewer, 1979; Mullen, Brown, \& Smith, 1992).

Models have been proposed to explain this impact of categorization on intergroup attitudes. Campbell (1956) and Tajfel (1969; Tajfel \& Wilkes, 1963) outlined accentuation and differentiation principles that provide frameworks for understanding the processes involved in categorical perception. These ideas have been expanded in various theoretical accounts such as Doise's (1978) Category Differentiation Model and in the form of the meta-contrast process (Oakes, Haslam, \& Turner, 1994) outlined by Self-Categorization Theory (Turner et al., 1987). While the emphasis of these accounts varies, what is common is the notion that categorization affords a psychological basis for understanding 'them' to be different to 'us', and it is this distinction between ingroups and outgroups that provides the prerequisite for intergroup discrimination.

\section{Methods and models for reducing intergroup bias}

The theoretical emphasis on psychologically represented intergroup differences provides the focus for social psychological interventions targeted at reducing prejudice. For many of these models the principal aim is to reduce cognitive differentiation between groups. Based on the theoretical accounts outlined above, this is a sensible strategy: if dichotomized categorical differentiation is a key contributor to ingroup favoritism, then to tackle the latter we must address the former. Allport (1954) was among the first to suggest that bringing groups closer together might provide the basis for improved intergroup relations. In Sherif's (1966) classic studies, it was cooperative contact, established after the imposition of a categorical distinction, that reduced ingroup favoritism. A sustained and extensive research program emerged from this notion that bringing groups together can be an important factor in creating more harmonious intergroup relations (e.g. Brewer \& Miller, 1984; Hewstone \& Brown, 1986; Pettigrew, 1997; Wright, Aron, McLaughlinVolpe, \& Ropp, 1997).

Although contact can have positive effects via affective mediators (e.g. Islam \& Hewstone, 1993), one key aspect of the approach is the establishment of perceived commonalities between the ingroup and outgroup. This idea is expressed in Gaertner and Dovidio's (2000) Common Ingroup Identity Model. This model arose to explain why cooperation and contact can be successful at reducing intergroup bias. In their 1989 and 1990 studies Gaertner and Dovidio (Gaertner et al., 1989, 1990) experimentally created intergroup contexts in which groups were either segregated and distinct, or were cooperatively integrated. Their findings, in line with the established effects of contact in varied settings, were that cooperative contact was successful at reducing intergroup bias. More importantly, they established that the formation of a common ingroup identity was the mediating process. Put another way, bias was reduced following cooperative contact because psychological boundaries between the ingroup and outgroup were broken down, and a new overarching group was formed that included former outgroup members.

Subsequent work has expanded on the varied conditions that increase the psychological overlap between the ingroup and outgroup, and that have bias-reducing effects. Goal relations 
and group interactions (Turner, 1982), perceptions of a common task or fate (Brown \& Abrams, 1986; Brown \& Wade, 1987; Gaertner et al., 1990), or even simply making a superordinate, or cross-cutting, categorization salient (Crisp, Ensari, Hewstone, \& Miller, 2003; Hornsey \& Hogg, 2000) can all reduce the cognitive differentiation between ingroups and outgroups, and thus, improve intergroup relations.

\section{Are boundaries always bad?}

Based on the work above, one might conclude that we should always strive to emphasize the overlapping characteristics of groups in order to create more harmonious intergroup relations. There are, however, some grounds for questioning whether promoting overlap is always the best way to reduce intergroup bias. Merging category boundaries and forming a superordinate representation has recently been found to sometimes worsen intergroup relations (e.g. Hornsey \& Hogg, 2000) or at least be a less effective strategy than alternative methods (Dovidio, Gaertner, \& Validzic, 1998; González \& Brown, 2003). Convergent evidence can be found in work on organizational mergers. Mergers can often cause the previously distinct subgroups to engage in heightened ingroup favoritism (see Terry \& Callan, 2001; Terry, Carey, \& Callan, 2001). These findings are clearly counter to the notion that recognizing overlapping characteristics, reducing differentiation, and merging intergroup representations, can always improve intergroup relations. It has recently been suggested that motivations to retain a distinctive social identity may provide an explanation for these divergent findings (see Hornsey \& Hogg, 2000; see also Terry et al., 2001). It is these motivations that we focus on here.

\section{Motivations to maintain distinctiveness}

Ingroup favoritism can not only be attributable to the psychological dichotomization of ingroups and outgroups. The Social Identity perspective (Tajfel \& Turner, 1979; Turner et al., 1987) outlines a number of motivational consequences, implications, and processes that might follow from social categorization and group affiliation. This perspective argues that we are not simply passive members of social groups-some groups mean more to us than others, and, when they do, we use them as an important source of self-esteem (Abrams \& Hogg, 1998; Ellemers, Spears, \& Doosje, 2002) or as a means to reduce subjective uncertainty (Hogg, 2000, 2001; see also Grieve \& Hogg, 1999; Hogg \& Mullin, 1999). Since such groups are valuable to self-conception, people want to maintain the perception of them as being (a) positive and (b) clearly distinguishable from other, relevant, comparison groups.

In the context of blurring intergroup boundaries, the motivation to reduce subjective uncertainty is particularly applicable. The loss of prescriptive ingroup norms and defined outgroup stereotypes that accompany weakened categorical differentiation is an unpleasant state for perceivers invested in the selfdefinitional benefits of ingroup affiliation. Hogg $(2000,2001)$ has illustrated how metacontrast and positive differentiation processes are accentuated in such conditions that promote uncertainty in the social context. Given the opportunity, the best way to enhance the positive distinctiveness of the ingroup from other groups is to differentially evaluate in favor of the ingroup. Supporting this perspective, group members do indeed appear compelled to differentiate their ingroup from similar outgroups on relevant dimensions of comparison (see Brewer, 1979; Brown \& Abrams, 1986; Roccas \& Schwartz, 1993; Tajfel, 1982; van Knippenberg \& Ellemers, 1990).

Importantly, the application of such motivational processes appears to be contingent upon the groups being perceived as important to self-definition. People who regard their ingroup as important-who are highly committed to it-can be considered high in ingroup identification (Spears, Doosje, \& Ellemers, 1997). Only when identification with the ingroup is high does weakened differentiation appear to motivate increased ingroup favoritism (Hogg \& Abrams, 1990; Hogg \& Turner, 1985; Jetten, Branscombe, Spears, \& McKimmie, 2003; Jetten, 
Spears, \& Manstead, 2001; Spears, Jetten, \& Scheepers, 2002). Indeed, in some recent research using minimal groups and a paradigm designed to test the effects on group perception of a merger between the ingroup and outgroup, van Leeuwen, van Knippenberg, and Ellemers (2003) found that pre-merger identification predicted post-merger intergroup attitudes. Specifically, prior to the merger identification did not predict intergroup evaluations. Following the merger, however, identification was positively correlated with ingroup favoritism. These findings are clearly indicative that, specifically for higher identifiers, creating category overlap could sometimes increase ingroup favoritism.

\section{The current research}

While there is now evidence that, under some circumstances, differentiation-based interventions for reducing intergroup bias may be of variable effectiveness, the precise nature of these conditions remains unspecified, and potential moderators empirically untested. From the above review of social identity research on distinctiveness threat, we can predict, however, that the effectiveness of differentiationreducing interventions will be related to preexisting levels of ingroup identification. We therefore hypothesized that a task designed to increase the perceived overlap between the ingroup and outgroup would be more effective at reducing intergroup bias for lower compared to higher identifiers. In the two studies reported here we tested this hypothesis.

\section{Experiment 1}

The aim of Experiment 1 was to test the moderating effect of ingroup identification on the effectiveness of a differentiation-reducing strategy analogous to those developed in the bias-reduction literature. We measured ingroup identification (with 'University' group membership) and then had participants simply list characteristics shared between the ingroup and outgroup (as a means of reducing ingroup-outgroup differentiation and creating category overlap), or not (the baseline comparison group). All participants then completed measures to assess ingroup favoritism. We expected this task to reduce ingroup favoritism, contingent on the extent of participants' ingroup identification.

\section{Method}

Participants and design A total of 168 undergraduates at the University of Birmingham (66 females, 72 males, with 30 participants failing to state their gender, mean age 20) were allocated across two between-subjects task conditions: baseline versus overlapping groups. Identification was a continuous variable, measured prior to the manipulation. Birmingham University students were the ingroup and students from a local rival university, Aston University, were the outgroup. These two universities are well-established in the UK Midlands and, due to geographical proximity, have an extensive history of intergroup comparison. As such, the comparison and cover story (see below) were relevant and credible to our participants. Participants received a small monetary payment for their involvement.

Procedure Participants were approached around campus by a female experimenter and asked to complete a short questionnaire concerned with opinions of students at different universities in the region. They were told that they would be asked some questions concerning their attitudes and feelings toward the different student groups. Participants first completed the pre-manipulation measure of ingroup identification. The four items were adapted from Jetten et al. (2003) and Luhtanen and Crocker (1992): 'I identify strongly with other Birmingham students', 'Being a Birmingham student is an important part of who I am', 'I feel strong ties with other Birmingham students', 'I feel a strong sense of solidarity with other Birmingham students' ( 1 not at all, 9 very much so). These items formed a reliable index $(\alpha=.879)$.

Participants in the baseline condition then simply completed the dependent measures. Prior to this, those in the experimental condition were presented with the following instructions: 
We would like you to think of up to five things that students at the University of Birmingham and students at the University of Aston may have in common (i.e. characteristics that are shared between the two groups).

Participants were instructed to write down the characteristics they thought of, before completing the dependent measures and being thanked and debriefed.

The effectiveness of this task for promoting the perception of increased intergroup overlap has been established in our previous research. Cocker and Crisp (2003, see also Cocker, 2004) gave 80 female undergraduate psychology students the task instructions described above, but relating to Psychology and English subject (major) groups. They were then asked to indicate the extent to which they perceived the ingroup and outgroup as 'groups that have numerous overlapping characteristics' (1 not at all, 9 very much so). Cocker and Crisp found that following the overlapping characteristics task participants perceived the in- and outgroup as having significantly more overlapping characteristics compared to participants in the baseline condition.

Dependent measures To measure ingroup favoritism participants were informed that another aim of the research was to gain students' opinions about how governmentallocated money to universities in the local region should be divided. There followed a list of 11 allocation options, ranging in $10 \%$ intervals from ' $100 \%$ to students at Birmingham $/ 0 \%$ to students at Aston', through a $50 \% / 50 \%$ allocation, to ' $0 \%$ to students at Birmingham $/ 100 \%$ to students at Aston' (adapted from Hornsey \& Hogg, 2000). Participants ticked their preferred allocation. We coded the ingroup percentage allocation as a measure of ingroup favoritism.

\section{Results and discussion}

We used moderated regression to assess the interaction of our continuous identification variable with the manipulation of group characteristics overlap (Aiken \& West, 1991; West, Aiken, \& Krull, 1996). We computed an interaction variable by contrast coding task condition as 0 and 1 (baseline vs. overlapping) and multiplying it by the centered identification scores for each participant. We then entered this interaction variable into a multiple regression on a second step, following the entry of the task and identification factors independently at step 1 . This analysis revealed a significant interaction between identification and task at step $2\left(R_{\mathrm{Ch}}^{2}=.028, F(1,164)=4.84, p<.05\right)$. We tested for differences between the baseline and overlapping conditions at lower and higher levels of ingroup identification at -1 and $+1 S D s$ respectively. This analysis revealed that at the lower level of identification bias was significantly lower for participants in the overlapping compared to baseline condition $(\beta=-.282$, $t=-2.59, p<.05)$. At the higher level of identification there was, however, no difference between task conditions $(\beta=.062, t=.563$, $p=.574)$. We also tested whether identification predicted bias within task conditions. Simple slopes analysis revealed that in the baseline condition identification was unrelated to bias ( $\beta=-.144, t=-1.30, p=.196)$, but following generation of overlapping characteristics identification was positively related to bias $(\beta=.213, t=2.00, p<.05)$ (see Figure 1$).$

To summarize, in line with our hypothesis we observed lower levels of bias for participants who completed the overlapping characteristics task-but only if they were lower identifiers. Furthermore, within task condition analysis revealed that the effectiveness of the overlapping characteristics task at reducing bias was related to participants' level of identification: the lower the level of pre-task identification reported by the participant, the greater the reduction in bias after completion of the task.

\section{Experiment 2}

Most work in the bias-reduction literature tests the effectiveness of interventions compared to a no-intervention baseline condition (arguably the most appropriate in terms of testing the practical efficacy of an intervention). In Experiment 1 this was also our strategy. It could be argued, however, that simply completing any 


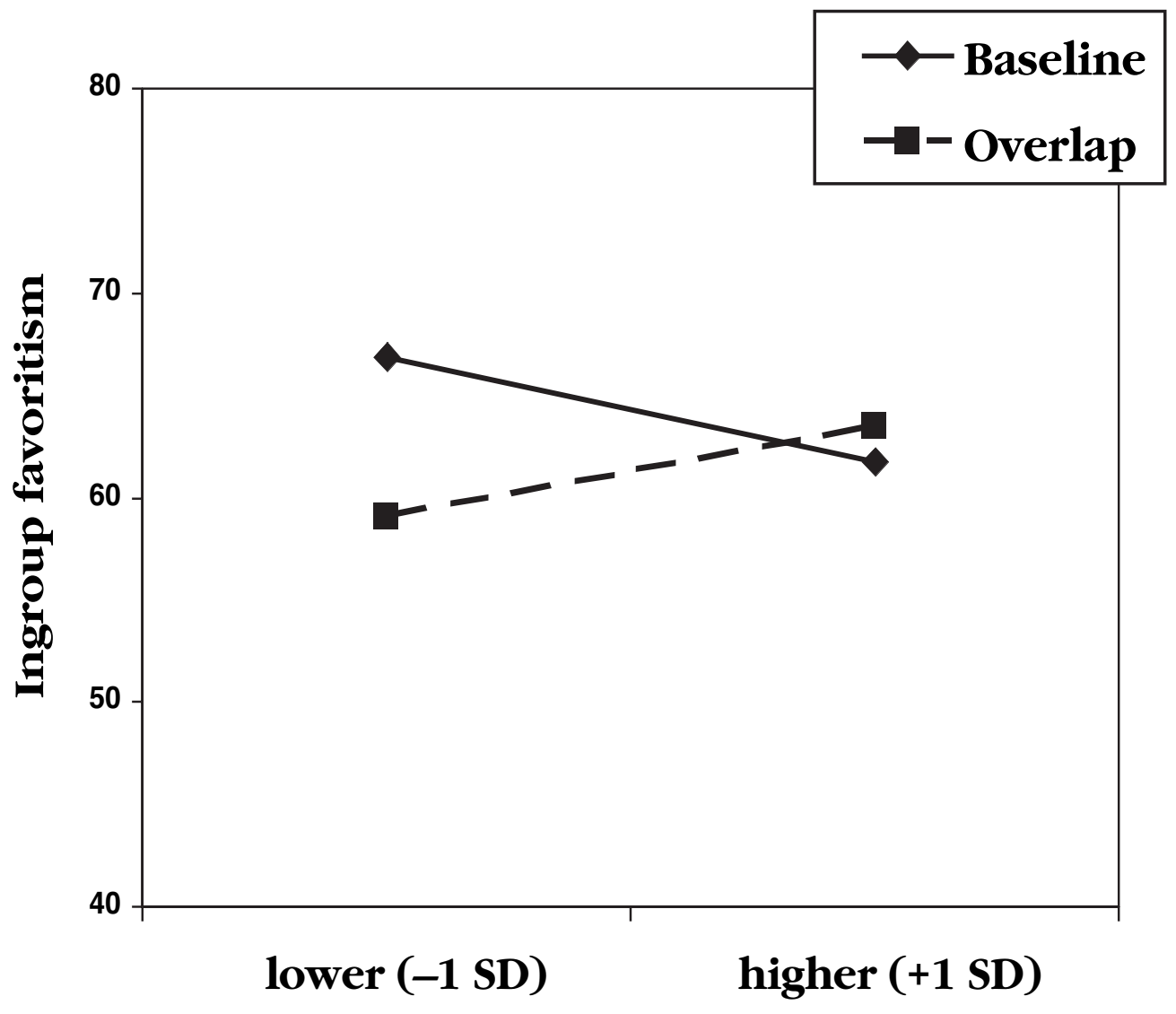

\section{Identification}

Figure 1. Ingroup favoritism as a function of overlapping characteristics and identification, Experiment 1.

task in the experimental condition could have had the same effects that we observed. This is because there was, notwithstanding the specific requirements of our task, an information load differential between the baseline and experimental conditions. Urban and Miller (1998), with reference to the crossed categorization literature, argued that complex task instructions can sometimes lead to mildly negative affect, which can correspondingly lead to negative judgments in intergroup contexts. With respect to the findings from Experiment 1, perhaps higher identifiers, for whom intergroup judg- ments are more relevant, reacted negatively to the load imposed by our task, but that lower identifiers were less sensitive to such load, the intergroup context being less important to them. Using a baseline task that requires exactly the same mental procedure as the experimental condition, but with reference to irrelevant categories would provide a comparative test of equal load conditions. Observing an impact of differential identification only when the task is related to the target groups would thus rule out the competing explanation that it is load induced by the task that is responsible 
for the effects. In Experiment 2 we therefore used a baseline condition in which participants generated overlapping characteristics between two categories that were unrelated to the target groups they later evaluated. We also tested different target groups and used a different evaluative measure to increase the generalizability of our findings.

\section{Method}

Participants and design Thirty-six high school students (25 females, 11 males, mean age 17) were allocated across two between-subjects task conditions: baseline (overlapping unrelated) versus overlapping (related). Identification was again a pre-manipulation measured variable. The target ingroup and outgroup were 'Southerners' and 'Northerners'-relating to where participants lived in the UK (all participants were members of the former group). This is a well-established and socially significant intergroup distinction in the UK, which is clearly delineated by accent.

Procedure Participants were tested in a classroom setting and informed by the male experimenter that the aim of the survey was to gain insight into the opinions that people from different regions of the UK had of one another. The procedure was as in Experiment 1 , except the identification items referred to 'Southerners'. The four identification items formed a reliable scale $(\alpha=.929)$. Participants generated 10 overlapping characteristics between 'Southerners' and 'Northerners' in the experimental condition and 10 overlapping characteristics between 'Cars and Bicycles' in the baseline condition. The latter constituted a baseline task of equivalent cognitive load, involving the same mental procedures as in the experimental condition, but focusing on categories unrelated to those evaluated in the later phase of the experiment. We extended the number of characteristics because the Northern/Southern distinction in the UK was expected to be more pervasive than categorization based on University affiliation. Hence we suspected a more extensive manipulation would be required.
Dependent measures In this experiment we used an alternative measure of ingroup favoritism, in order to improve the generalizability of our findings. Evaluations were assessed with an attitude thermometer (see Haddock, Zanna, \& Esses, 1993). Participants were asked to indicate their general attitudes toward Southerners and Northerners on separate thermometers (0 extremely unfavorable, 100 extremely favorable). They were asked to mark a cross on the thermometers which reflected their initial feeling that came to mind on reading the category labels 'Southerners' and 'Northerners', and to write the exact number beside the cross that they made.

\section{Results and discussion}

Evaluations Again we used moderated regression to assess the interactive effects on bias of identification and the characteristics task manipulation. There was a significant interaction between identification and task $\left(R_{\mathrm{Ch}}^{2}=\right.$ $.099, F(1,32)=8.70, p<.01)$. As in Experiment 1 we tested for differences between the baseline and overlapping conditions at lower and higher levels of identification $(-1$ and +1 SDs respectively). At the lower level of identification bias was again significantly lower for participants in the overlapping compared to baseline condition $(\beta=-.385, t=-2.46, p<.05)$. Interestingly, at the higher level of identification there was also a marginally significant trend for bias to be higher following the overlapping task compared to baseline $(\beta=.304, t=1.90$, $p=.067)$. Within task condition simple slopes analysis revealed that in the baseline condition identification was unrelated to bias $(\beta=.366$, $t=1.67, p=.112$ ), but following generation of overlapping characteristics identification was positively related to bias $(\beta=.854, t=6.15$, $p<.0005$ ) (see Figure 2).

In this experiment we therefore replicated the effects observed in Experiment 1 with tasks of equivalent informational load. When participants thought about overlapping characteristics between the ingroup and outgroup bias was reduced, but only for lower identifiers. For higher identifiers, thinking about overlapping characteristics did not reduce bias, and actually 


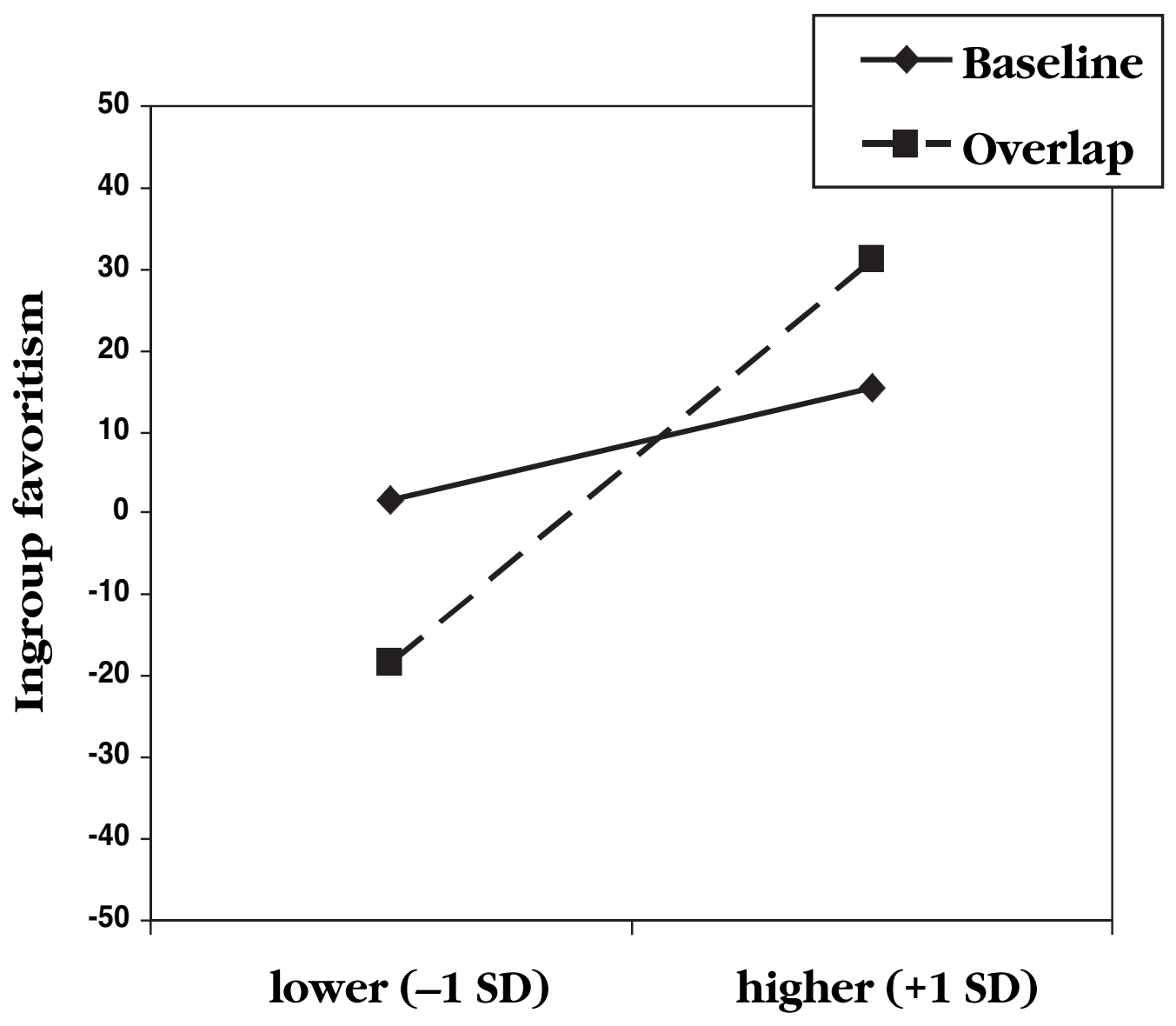

\section{Identification}

Figure 2. Ingroup favoritism as a function of overlapping characteristics and identification, Experiment 2.

led to a marginally significant increase. In sum, the effectiveness of the overlapping characteristics task was again proportional to the level of pre-task ingroup identification: the task was more effective at reducing intergroup bias for participants who reported lower levels of pretask identification.

\section{General discussion}

In this research we set out to examine the conditions under which interventions designed to reduce intergroup bias may be differentially effective. In two experiments, using different social categories and contexts, and measures and manipulations, we found consistent evidence that the overlapping characteristics task reduced bias for lower identifiers, but not for higher identifiers. Furthermore, thinking about characteristics that overlapped between the ingroup and outgroup reduced ingroup favoritism to an extent proportional to pre-task levels of ingroup identification. That is to say, for participants who completed the overlapping 
characteristics task, the lower their level of pretask identification, the lower their bias subsequent to the task. We discuss these findings in the context of recent developments in the biasreduction literature.

\section{Theoretical implications}

These findings provide strong evidence that the extent of perceivers' ingroup identification ${ }^{1}$ can predict the effectiveness of interventions designed to reduce intergroup bias. Much work on contact, categorization, and conflict-resolution has incorporated the view that differentiation is divisive, and that fostering intergroup overlap is therefore one of the key elements for improving intergroup relations. There is a large corpus of empirical evidence in support of this, however, there is also mounting evidence that the effectiveness of such interventions can vary (Dovidio et al., 1998; González \& Brown, 2003). Indeed, sometimes such interventions may actually increase bias (e.g. Hornsey \& Hogg, $2000)$. This invites the question of what moderates these quite different outcomes. Ingroup identification, an affective commitment to ingroups associated with motivations to preserve positive distinctiveness, appears to be one such moderator. In the two studies reported here, we consistently observed the bias-reducing effects of category overlap to be moderated by ingroup identification. Ingroup identification may therefore account for some previous divergence in the literature, and thus potentially play an important role in the future development of models of bias-reduction.

According to the Social Identity perspective, some group affiliations are more important than others, especially for some people, some of the time. Differences in identification should thus predict when social identity motivations will come into play. For lower identifiers, group membership contributes little to self-identity, and so any weakening of categorical boundaries will likely lead to the formation of an inclusive representation that includes former outgroupers. For higher identifiers, however, group membership provides a means of defining oneself, in particular in comparison with a relevant outgroup (Hogg, 2001). Interventions that therefore serve to weaken this valued distinctiveness might, by virtue of the threat caused by the erosion of intergroup boundaries, lead higher identifiers to maintain a high level of ingroup favoritism to protect threatened distinctiveness.

Higher identifiers in the two studies reported here appeared to do just that. In Experiment 1, compared to baseline, they maintained a high level of ingroup favoritism following the overlap task, and in Experiment 2 they even became more ingroup favoring after the task. ${ }^{2}$ These studies thus take an important step forward in illustrating the importance of considering social identity motivations when developing intervention strategies for reducing intergroup bias.

We must, however, be careful not to take these findings as unequivocal support for the distinctiveness-threat mechanism outlined by the social identity perspective. For instance, Diehl (1988) argues that increases in intergroup similarity (one potential consequence of our overlapping characteristics task) leads to increased bias against outgroups, whilst increased interpersonal similarity reduces bias against outgroups. Here then, it is plausible that following the overlapping characteristics task lower identifiers switched to responding in interpersonal terms (less bias), whereas higher identifiers responded in intergroup terms (increased bias). Future research on distinctiveness-threat should aim to include potential mediating measures in order to delineate more fully the precise processes underlying such effects.

We should also acknowledge other competing explanations for the effects we observed. In both experiments we found that while lower identifiers were less ingroup favoring after the overlapping characteristics task, higher identifiers remained ingroup favoring. It may be that specifically for higher, but not lower identifiers, additional conditions are required for intergroup overlap to reduce intergroup bias. For instance, perhaps it is not that higher identifiers find the realization of overlapping characteristics with the outgroup threatening, but rather that they have a more solidified representation 
of how different the ingroup is from the outgroup. For higher identifiers it may be that the augmenting conditions specified by the contact hypothesis (e.g. cooperation, acquaintance potential) are especially relevant.

Finally, we should also acknowledge that although our overlapping characteristics task was designed to capture the merged representation element of differentiation-reducing strategies, strategies such as contact and forming a common ingroup identity incorporate other elements as well. For instance, contact can reduce intergroup anxiety (see Islam \& Hewstone, 1993), but this was not an element in the overlapping characteristics task that we employed in our experiments. Similarly, research on the Common Ingroup Identity Model recategorizes subgroup members at a higher level of inclusiveness, but this was not necessarily a consequence of our overlapping characteristics task. Future research will need to establish whether, and how, ingroup identification is relevant to specific intervention strategies like contact and the formation of a common ingroup identity.

\section{Practical implications}

The finding that perceivers can react in dramatically divergent ways to the same intervention has significant implications for the application of social psychological models to real contexts of intergroup conflict. The findings we report suggest that a 'one size fits all' approach to reducing intergroup bias may not be most effective. For some people (lower identifiers) improved intergroup relations may be likely, but for others (higher identifiers) encouraging the dissolution of intergroup boundaries may be less effective, and possibly even accentuate ingroup favoritism.

The different ways in which lower and higher identifiers react to changes in intergroup distinctiveness calls for more tailored intervention strategies, suited to specific populations. Indeed, recent approaches to bias-reduction have acknowledged that differentiation, in contrast to assimilation, can sometimes play an important role. If higher identifiers react negatively to the erosion of intergroup boundaries, then one option is to strengthen those boundaries within the context of a more inclusive intergroup context. This 'simultaneous categorization' approach (Hornsey \& Hogg, 2000; or 'Dual identity approach' Gaertner \& Dovidio, 2000) can yield more positive effects for intergroup relations compared to the complete abandonment of subgroup identities (see González \& Brown, 2003). Interestingly, this parallels a similar appreciation of the importance of differentiation in the contact literature. Hewstone \& Brown's (1986) Mutual Intergroup Differentiation Model outlines the need to maintain category distinctiveness in order to allow generalization of positive affect from the individual outgroup member to the outgroup as a whole. On the basis of the findings we report here, such 'differentiation-preserving' interventions may work particularly well for people who strongly identify with their ingroup.

Research developing interventions to reduce intergroup bias has sometimes yielded disparate findings. In this research we tested whether motivations associated with maintaining a distinct social identity could account for such disparities. We hypothesized that differences in the extent to which participants identified with their ingroup would predict whether, and when, reducing intergroup differentiation would reduce intergroup bias. Confirming these expectations, we found that our overlapping characteristics task reduced bias for lower identifiers, but not for higher identifiers. Furthermore, the extent to which ingroup favoritism was reduced was proportional to pre-task levels of ingroup identification: the lower the level of pre-task identification, the lower was bias subsequent to the task. The findings suggest that ingroup identification might play a central role in how future models of bias-reduction should develop to tackle the complexity of intergroup affiliations, motivations, and evaluations. Developing such multifaceted models for reducing intergroup bias is the challenge for future work. 


\section{Notes}

1. We are keen to point out that identification is not, as our conceptualization might imply, only an individual difference variable. People's identification with different social groups can vary, and contextual factors exert a strong influence on identification, and correspondingly, the tendency for people to behave in line with social identity motivations.

2. We note that the increase in bias observed following the characteristics task at higher levels of identification could, in part, be attributable to changes made to target groups and measures in Experiment 2.

\section{Acknowledgments}

This research was funded by a Leverhulme Trust grant (F/00094/H) directed by R. J. Crisp. We thank James Bacon for his assistance in data collection for Experiment 2.

\section{References}

Abrams, D., \& Hogg, M. A. (1998). Prospects for research in group processes and intergroup relations. Group Processes E Intergroup Relations, 1, 7-20.

Aiken, L. S., \& West, S. G. (1991). Multiple regression: Testing and interpreting interactions. London: Sage.

Allport, G. W. (1954). The nature of prejudice. Garden City, NY: Doubleday.

Brewer, M. B. (1979). Ingroup bias in the minimal intergroup situation: A cognitive-motivational analysis. Psychological Bulletin, 86, 307-324.

Brewer, M. B. (1991). The social self-on being the same and different at the same time. Personality and Social Psychology Bulletin, 17, 475-482.

Brewer, M. B., \& Miller, N. (1984). Beyond the contact hypothesis: Theoretical perspectives on desegregation. In N. Miller \& M. B. Brewer (Eds.), Groups in contact: The psychology of desegregation (pp. 281-302). Orlando, FL: Academic Press.

Brown, R. J., \& Abrams, D. (1986). The effects of intergroup similarity and goal interdependence on intergroup attitudes and task performance. Journal of Experimental Social Psychology, 22, 78-92.

Brown, R. J., \& Wade, G. (1987). Superordinate goals and intergroup behaviour: The effect of role ambiguity and status on intergroup attitudes and task performance. European Journal of Social Psychology, 17, 131-142.
Campbell, D. T. (1956). Enhancement of contrast as a composite habit. Journal of Abnormal and Social Psychology, 53, 350-355.

Cocker, R. M. (2004). Intergroup overlap and intergroup evaluation: The moderating role of ingroup identification. Unpublished MPhil dissertation. University of Birmingham, UK.

Cocker, R. M., \& Crisp, R. J. (2003). Shared characteristics and perceived overlap. Unpublished dataset, University of Birmingham, UK.

Crisp, R. J., Ensari, N., Hewstone, M., \& Miller, N. (2003). A dual-route model of crossed categorization effects. In W. Stroebe \& M. Hewstone (Eds.), European review of social psychology (Vol. 13, pp. 35-74). Philadelphia, PA: Psychology Press.

Crisp, R. J., \& Hewstone, M. (1999). Differential evaluation of crossed category groups: Patterns, processes, and reducing intergroup bias. Group Processes E Intergroup Relations, 2, 307-333.

Crisp, R. J., Hewstone, M., \& Rubin, M. (2001). Does multiple categorization reduce intergroup bias? Personality and Social Psychology Bulletin, 27, 76-89.

Deschamps, J. C., \& Doise, W. (1978). Crossed category memberships in intergroup relations. In H. Tajfel (Eds.), Differentiation between social groups (pp. 141-158). Cambridge, UK: Cambridge University Press.

Diehl, M. (1988). Social identity and minimal groups-the effects of interpersonal and intergroup attitudinal similarity on intergroup discrimination. British Journal of Social Psychology, 27, 289-300.

Doise, W. (1978). Groups and individuals: Explanations in social psychology. Cambridge, UK: Cambridge University Press.

Dovidio, J. F., Gaertner, S. L., \& Validzic, A. (1998). Intergroup bias: Status, differentiation and a common ingroup identity. Journal of Personality and Social Psychology, 75, 109-120.

Ellemers, N., Spears, R., \& Doosje, B. (2002). Self and social identity. Annual Review of Psychology, 53, 161-186.

Gaertner, S. L., \& Dovidio, J. F. (2000). Reducing intergroup bias: The common ingroup identity model. Philadelphia, PA: Psychology Press/Taylor \& Francis.

Gaertner, S. L., Mann, J. A., Dovidio, J. F., Murrell, A. J., \& Pomare, M. (1990). How does cooperation reduce intergroup bias? Journal of Personality and Social Psychology, 59, 692-704.

Gaertner, S. L., Mann, J. A., Murrell, A. J., \& 
Dovidio, J. F. (1989). Reducing intergroup bias: The benefits of recategorization. Journal of Personality and Social Psychology, 57, 239-249.

González, R., \& Brown, R. J. (2003). Generalization of positive attitude as a function of subgroup and superordinate group identifications in intergroup contact. European Journal of Social Psychology, 33, 195-214.

Grieve, P. G., \& Hogg, M. A. (1999). Subjective uncertainty and intergroup discrimination in the minimal group situation. Personality and Social Psychology Bulletin, 25, 926-940.

Haddock, G., Zanna, M. P., \& Esses, E. M. (1993). Asserting the structure of prejudicial attitudes: The case of attitudes towards homosexuals. Journal of Personality and Social Psychology, 65, 1105-1118.

Hewstone, M., \& Brown, R. (1986). Contact is not enough: An intergroup perspective on the 'Contact Hypothesis'. In M. Hewstone \& R. Brown (Eds.), Contact and conflict in intergroup encounters (pp. 1-44). Oxford, UK: Blackwell.

Hogg, M. A. (2000). Subjective uncertainty reduction through self-categorization: A motivational theory of social identity processes. European Review of Social Psychology, 11, 223-255.

Hogg, M. A. (2001). Self-categorization and subjective uncertainty resolution: Cognitive and motivational facets of social identity and group membership. In J. P. Forgas, K. D. Williams, \& L. Wheeler (Eds.), The social mind: Cognitive and motivational aspects of interpersonal behavior (pp. 323-349). New York: Cambridge University Press.

Hogg, M. A., \& Abrams, D. (1990). Social motivation, self-esteem and social identity. In D. Abrams \& M. A. Hogg (Eds.), Social identity theory: Constructive and critical advances (pp. 28-47). New York: Springer-Verlag.

Hogg, M. A., \& Mullin, B. A. (1999). Joining groups to reduce uncertainty: Subjective uncertainty reduction and group identification. In D. A. Abrams \& M. A. Hogg (Eds.), Social identity and social cognition (pp. 249-279). Oxford, UK: Blackwell.

Hogg, M. A., \& Turner, J. C. (1985). Interpersonal attraction, social identification and psychological group formation. European Journal of Social Psychology, 15, 51-66.

Hornsey, M. J., \& Hogg, M. A. (2000). Subgroup relations: A comparison of mutual intergroup differentiation and common ingroup identity models of prejudice reduction. Personality and Social Psychology Bulletin, 26, 242-256.

Islam, M. R., \& Hewstone, M. (1993). Dimensions of contact as predictors of intergroup anxiety, perceived out-group variability, and out-group attitude: An integrative model. Personality and Social Psychology Bulletin, 19, 700-710.

Jetten, J., Branscombe, N. R., Spears, R., \& McKimmie, B. M. (2003). Predicting the paths of peripherals: The interaction of identification and future possibilities. Personality and Social Psychology Bulletin, 29, 130-140.

Jetten, J., Spears, R., \& Manstead, A. S. R. (2001). Similarity as a source of discrimination: The role of group identification. European Journal of Social Psychology, 31, 621-640.

Luhtanen, R., \& Crocker, J. (1992). A collective self-esteem scale: Self-evaluation of one's social identity. Personality and Social Psychology Bulletin, 18, 302-318.

Miller, N., Brewer, M. B., \& Edwards, K. (1985). Cooperative interaction in desegregated settings: A laboratory analog. Journal of Social Psychology, 22, 103-122.

Mullen, B., Brown, R., \& Smith, C. (1992). Ingroup bias as a function of salience, relevance, and status: An integration. European Journal of Social Psychology, 22, 103-122.

Oakes, P. J., Haslam, S. A., \& Turner, J. C. (1994). Stereotyping and social reality. Oxford, UK: Blackwell.

Pettigrew, T. F. (1997). Generalized intergroup contact effects on prejudice. Personality and Social Psychology Bulletin, 23, 173-185.

Pettigrew, T. F. (1998). Intergroup contact theory. Annual Review of Psychology, 49, 65-85.

Roccas, S., \& Schwartz, S. H. (1993). Effects of intergroup similarity on intergroup relations. European Journal of Social Psychology, 23, 581-595.

Sherif, M. (1966). Group conflict and cooperation. London: Routledge Kegan Paul.

Spears, R., Doosje, B., \& Ellemers, N. (1997). Self-stereotyping in the face of threats to group status and distinctiveness: The role of group identification. Personality and Social Psychology Bulletin, 23, 538-553.

Spears, R., Jetten, J., \& Scheepers, D. (2002). Distinctiveness and the definition of collective self. In A. Tesser, D. A., Stapel, \& J. Wood (Eds.), Self and motivations: Emerging psychological perspectives (pp. 147-171). Washington, DC: American Psychological Association.

Tajfel, H. (1969). Cognitive aspects of prejudice. Journal of Social Issues, 25, 79-97.

Tajfel, H. (1982). Social psychology of intergroup relations. Annual Review of Psychology, 33, 1-39.

Tajfel, H., Billig, M. G., Bundy, R. P., \& Flament, C. (1971). Social categorization and intergroup 
behavior. European Journal of Social Psychology, 1, 149-178.

Tajfel, H., \& Turner, J. C. (1979). An integrative theory of intergroup conflict. In W. G. Austin \& S. Worchel (Eds.), The social psychology of intergroup relations (pp. 33-47). Monterey, CA: Brooks/Cole.

Tajfel, H., \& Wilkes, A. L. (1963). Classification and quantitative judgment. British Journal of Psychology, 54, 101-113.

Terry, D. J., \& Callan, V. J. (2001). In-group bias in response to an organizational merger. Group dynamics: Theory, research, and practice, 2, 67-81.

Terry, D. J., Carey, C. J., \& Callan, V. J. (2001). Employee adjustment to an organizational merger: An intergroup perspective. Personality and Social Psychology Bulletin, 27, 267-280.

Turner, J. C. (1982). Towards a cognitive redefinition of the social group. In $\mathrm{H}$. Tajfel (Ed.), Social identity and intergroup relations, Cambridge, UK: Cambridge University Press.

Turner, J. C., Hogg, M. A., Oakes, P. J., Reicher, S. D., \& Wetherell, M. S. (1987). Re-discovering the social group: A self-categorization theory. Oxford, UK: Blackwell.

Urban, L. M., \& Miller, N. M. (1998). A theoretical analysis of crossed categorization effects: A metaanalysis. Journal of Personality and Social Psychology, 74, 894-908.

van Knippenberg, A., \& Ellemers, N. (1990). Social identity and intergroup differentiation process. In W. Stroebe \& M. Hewstone (Eds.), European review of social psychology (Vol. 1, pp. 137-169).

Chichester, UK: Wiley. van Leeuwen, E., van Knippenberg, D., \& Ellemers, N. (2003). Continuing and changing group identities: The effects of merging on social identification and ingroup bias. Personality and Social Psychology Bulletin, 29, 697-690.

West, S. G., Aiken, L. S., \& Krull, J. L. (1996). Experimental personality designs: Analyzing categorical by continuous variable interactions. Journal of Personality, 64, 1-48.

Wright, S. C., Aron, A., McLaughlin-Volpe, T., \& Ropp, S. A. (1997). The extended contact effect: Knowledge of cross-group friendships and prejudice. Journal of Personality and Social Psychology, 73, 73-90.

Paper received 1 May 2004; revised version accepted 4 October 2004.

\section{Biographical notes}

RICHARD J. CRISP is currently Reader in Social Psychology at the University of Birmingham. His research interests span social cognition and intergroup relations, with particular emphasis on the antedecents, processes, and consequences of multiple social categorization.

SARAH R. BECK is currently Lecturer in Developmental Psychology at the University of Birmingham. Her research interests include children's and adults' counterfactual thinking and children's cognitive development. 